\title{
A Non-Inverting Soft Switching Buck-Boost Converter (Closed Loop) and It's Performance Against Various Converters
}

\author{
R. Senthil kumar, N. Vishaal Balaji, N. Venkatesh, J.Ajay
}

\begin{abstract}
A Non-inverting soft switching buck-boost Converter is presented. One of the major hurdles that every converters face is switching losses. This loss is associated with the switches that are used to build the converters. To overcome this, magnetic coupling effect has been introduced to the proposed converter. This magnetic coupling effect helps the converter to obtain an adjustable soft switching range. Theoretically, it has been said that soft switching results in zero switching losses. That way, the losses due to switching can be neglected and that helps in improving the overall efficiency. In the paper, we have proposed a soft switching non inverting buckboost converter and compared its performance characteristics with various other converters.
\end{abstract}

Keywords: Coupling, Inductor, Capacitor, zero voltage switching, Soft switching, Hard switching, Power converters, DC-DC, Coupled Inductor, Non-inverting, Buck-Boost Converter, Zeta Converter

\section{INTRODUCTION}

A converter used in electrical applications converts the electrical power from any one form to another. The converters are classified into different types, based on the type of the power given as input and the converted output. They are DC-AC, DC-DC, AC-AC and AC-DC. Let us mainly focus on the DC-DC converter. The DC-DC converter, converts a fixed DC input to a variable DC voltage. It has applications ranging from very low levels of power like small batteries to extremely high-power applications like in power systems. They have been efficient and better alternatives compared to vibrators, which were used to convert the input power to $\mathrm{AC}$ and later given to a transformer for stepping down voltage and then fed to rectifier to get a DC output. And for high power applications, generators of the desired output voltage were used to give the DC output. This conversion was very inefficient as there was a very high loss of power in the circuit. So, power switches were used to build these converters. They were comparatively better and viable alternatives to the earlier methods of power conversion. Although these are very efficient compared to the olden techniques, they are also not perfect. As the switching frequency increases it is important to reduce the loss that take place in the converter.

Revised Manuscript Received on May 25, 2020.

* Correspondence Author

R. Senthil Kumar*, Department of Electrical and Electronics Engineering Thiagarajar College of Engineering, Madurai, Tamil Nadu, India.

N. Vishaal Balaji, Department of Electrical and Electronics Engineering, SRM Institute of Science and Technology, Kattankulathur, India.

N. Venkatesh, Department of Electrical and Electronics Engineering, SRM Institute of Science and Technology, Kattankulathur, India.

J. Ajay, Department of Electrical and Electronics Engineering, SRM Institute of Science and Technology, Kattankulathur, India.

(C) The Authors. Published by Blue Eyes Intelligence Engineering and Sciences Publication (BEIESP). This is an open access article under the CC BY-NC-ND license (http://creativecommons.org/licenses/by-nc-nd/4.0/)
This loss is called as switching loss. Switching losses are associated with the switches used and they occur due to the transition of the switches from one state to another state. To avoid switching losses in converters, we use a technique called soft switching[1]. To understand soft switching, we need to understand about hard switching. As we know, a transistor is a three-terminal device with a simple logic - the flow of electricity in the third pin allows the passage of current between the other two terminals. So, the transistor is in either on or off state. The transition from on to off state or the reverse is not instantaneous, but consumes a very short time. In this transition period, some energy is wasted which are switching losses. These amount to a higher percentage of losses in power converters converters[3]. Switches that operate on larger voltages have larger losses. These losses have an effect on the overall efficiency of the converter[4]. Switching losses occur when the voltage and current waveforms intersect (Refer fig.). Soft switching reduces this loss by either reducing the voltage or current to zero, so that the power loss is virtually zero as power is tantamount to the product of voltage past the switch and the current[2]. Depending on which parameter is to be reduced to zero, soft switching is classified into two types:

1) zero voltage switching

2) zero current switching

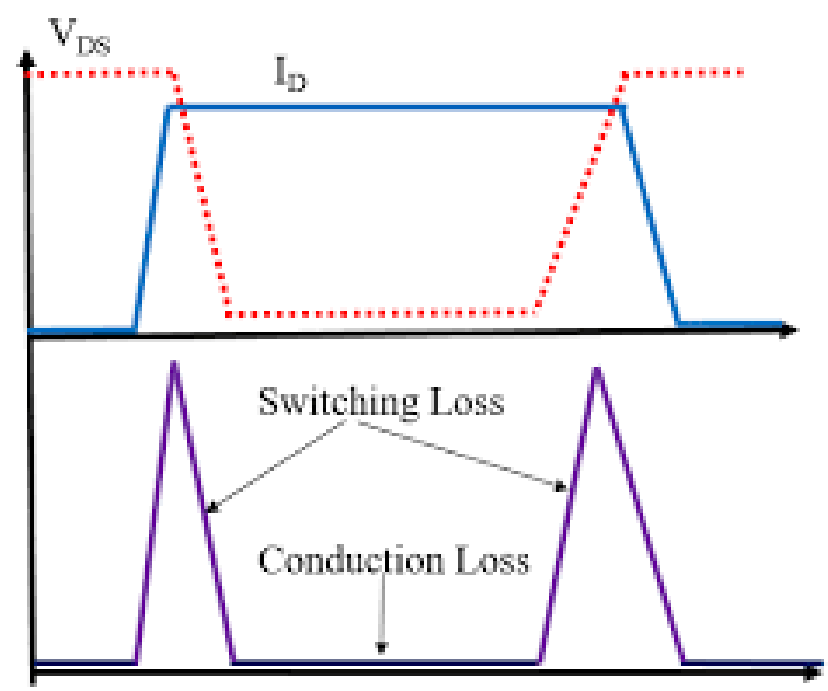

Time

Fig. 1. Soft Switching

$\mathrm{P}_{\text {loss }}=\mathrm{V}^{*} \mathrm{I}$

Soft switching improves the overall efficiency of the converter.

Published By:

Blue Eyes Intelligence Engineering

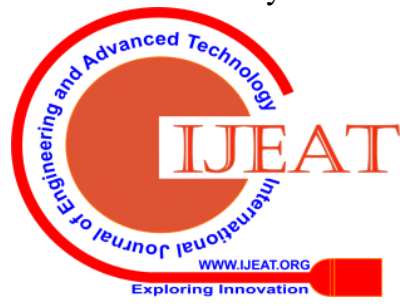




\section{A Non-Inverting Soft Switching Buck-Boost Converter (Closed Loop) and It's Performance Against Various Converters}

To achieve this, an external circuit is used. This circuit helps in overlapping the voltage and current waveforms. There are two types: self resonance and forced resonance. A self oscillating circuit is used in case of self resonance. With precise timing of the transistor commutation, results a narrow offset in current and voltage waveforms. Forced resonance uses various inputs to calculate the timing required to force a resonance to offset the current and voltage waveforms. Soft switching is further classified into three types based on the circuits used for obtaining it.
1) Passive auxiliary circuit based soft switching
2) Auxiliary circuit based soft switching
3) Non-auxiliary circuit based soft switching

Since using non-auxiliary circuit based soft switching results in large current ripples it is avoided. Passive auxiliary circuit based switching does not allow bidirectional soft-switching. Auxiliary circuit switching results in reducing the switching losses but additional control and driver circuits have to be used resulting in complexity of the circuit. In this paper, using coupled inductor a non-inverting soft switching buckboost converter (closed loop) is presented and its performance characteristics are compared with other converters.

\section{OPERATION}

The converter operation can be explained by splitting it into several stages.

Stage 1: All the switches are switched off. 'Capacitors charge during this phase.

Stage 2: The diodes connected across the switches s2 and s4 will be turned on. In this phase the voltage across vs2 and vs4 will be approaching zero

Stage 3: Now switches s2 and s4 are turned on.

Stage 4: All the four switches are turned off in this phase.

Stage 5: Diodes across s1 and s3 are turned on like stage 2, therefore voltage across the switches s1 and s3 approaches to zero.

Stage 6: Switches s1 and s3 are turned on similar to stage 3. During this stage, power is stocked in the Inductor (L) .

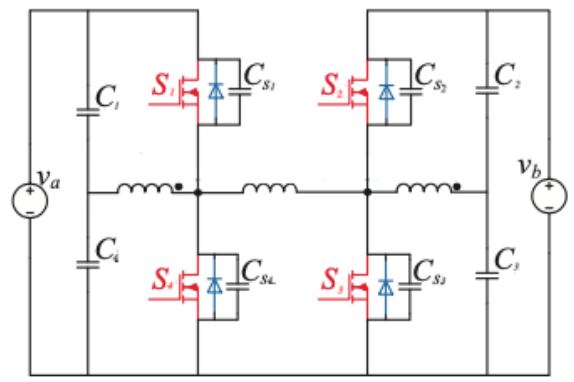

$\mathrm{i}_{\mathrm{s} 1}=\mathrm{v}_{\mathrm{a}} \mathrm{DT}(1-\mathrm{D})(1-\mathrm{D}+\mathrm{kD}) / 2 \operatorname{Lr}\left(1-\mathrm{k}^{2}\right)>\mathrm{i}_{\mathrm{b}}$

$\mathrm{i}_{\mathrm{s} 2}=\mathrm{v}_{\mathrm{a}} \mathrm{DT}(1-\mathrm{D})(\mathrm{k}+\mathrm{D}-\mathrm{kD}) / 2 \operatorname{Lr}\left(1-\mathrm{k}^{2}\right)>\mathrm{i}_{\mathrm{b}}$

$\mathrm{v}_{\mathrm{o}}=\mathrm{V}_{\text {in }} * \mathrm{D} /(1-\mathrm{D})$

The above equations are the conditions for achieving soft switching[6]. Where,

$\mathrm{Va}=$ Voltage from source $\mathrm{A}$.

$\mathrm{Vb}=$ Voltage from source $\mathrm{B}$.
$\mathrm{D}=$ Duty Cycle

$\mathrm{Lr}=$ Auxiliary Inductor

$\mathrm{M}=\mathrm{kLr}=$ Mutual Inductance

$\mathrm{V}_{\mathrm{o}}=$ Output Voltage

$\mathrm{V}_{\text {in }}=$ Input Voltage

\section{SIMULATION}

Non-inverting soft switching buck-boost converter with closed loop. Proposed converter's circuit diagram is shown in fig. 2. Simulated results of the proposed converter are also provided below. Simulated results includes voltage across the switches (refer fig.2.1), capacitor currents (refer fig.2.2) and inductor currents (refer fig.2.3).

\section{A. Non-Inverting Buck-Boost Converter}

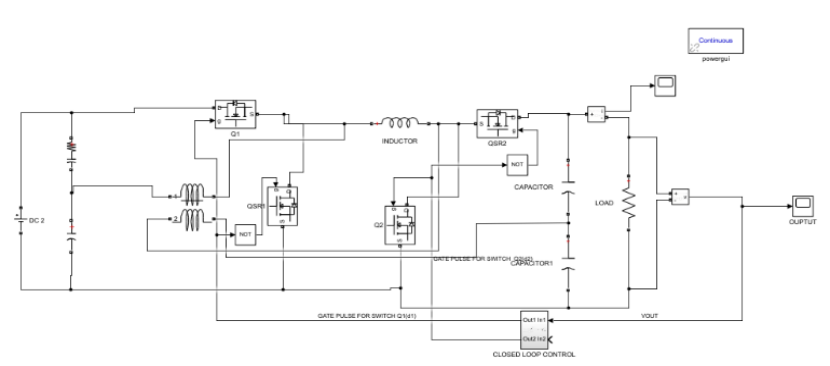

Fig. 2. Proposed circuit diagram

Values of the components:

Input voltage $-12 \mathrm{~V}$

Main inductor $-780 \mathrm{nH}$

Auxiliary inductor - 50mH

Resistor - 100 ohms

Capacitor $-4.7 \mathrm{uF}, 1 \mathrm{~F}$

\section{Simulated result:}

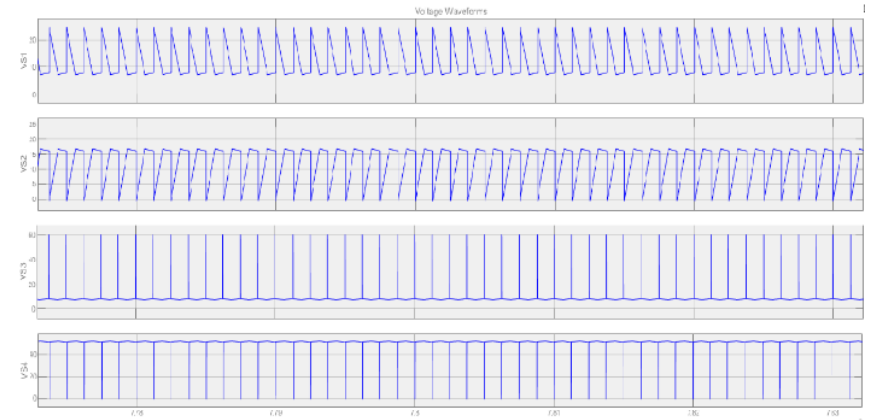

Fig.2.1. Voltages across the switches

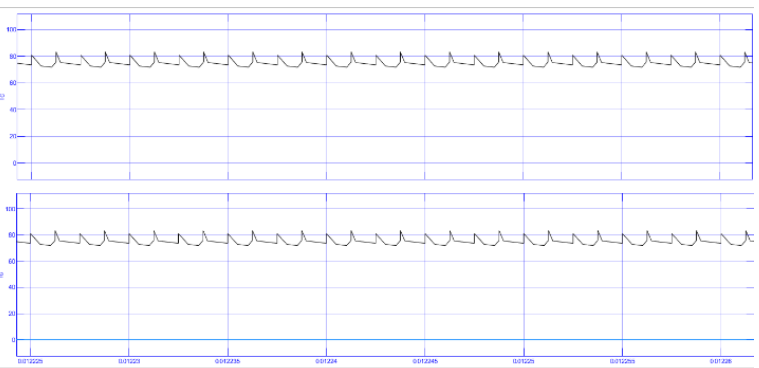

Fig.2.2. Capacitor current

Published By:

Blue Eyes Intelligence Engineering

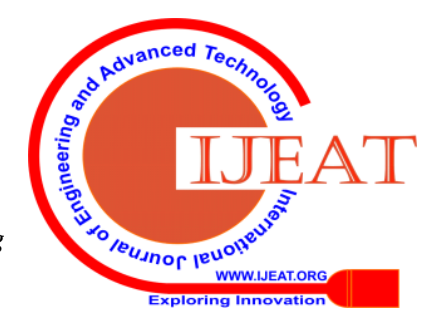



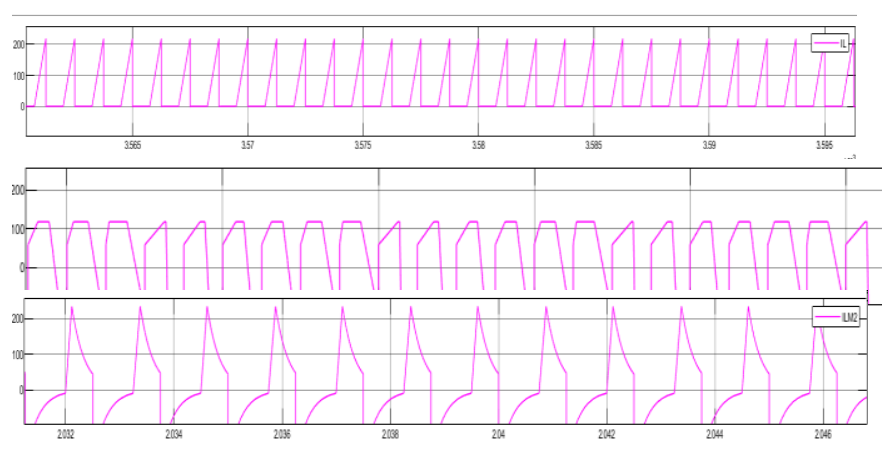

Fig.2.3. Inductor currents

\section{B. Zeta Converter}

Zeta converter circuit diagram along with its simulated results are presented below. The parameter values are same as that used in case of non-inverting soft switching buckboost converter. The simulated results include output voltage (Refer fig.3.1), inductor current (Refer fig. 3.2) and capacitor current (Refer fig. 3.3).

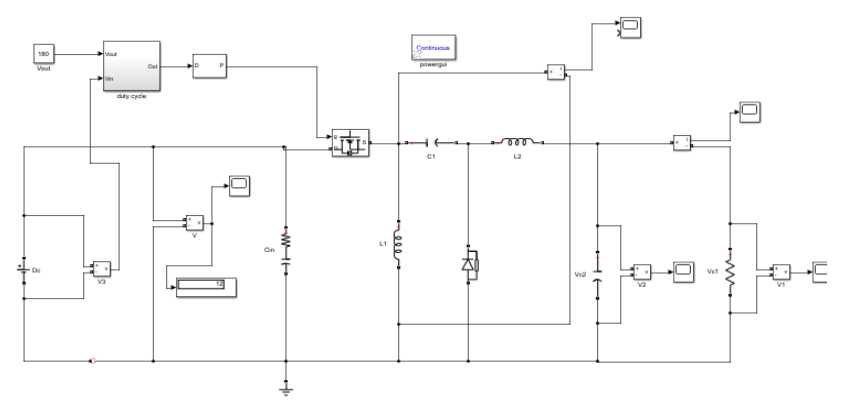

Fig.3. Zeta circuit diagram

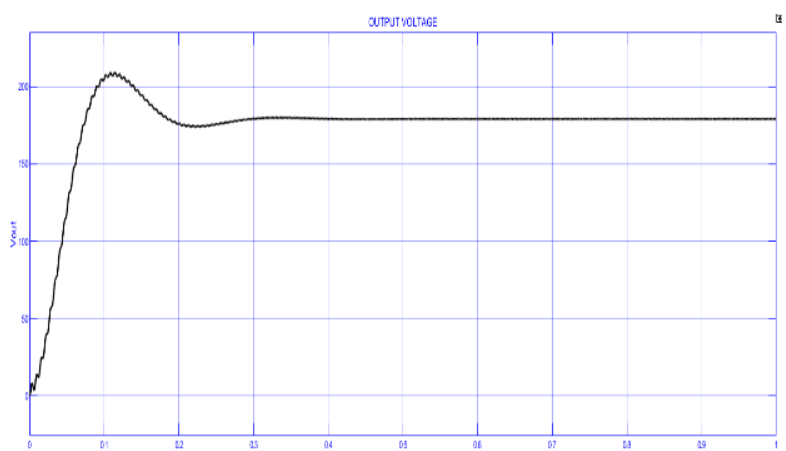

Fig.3.1. Output voltage

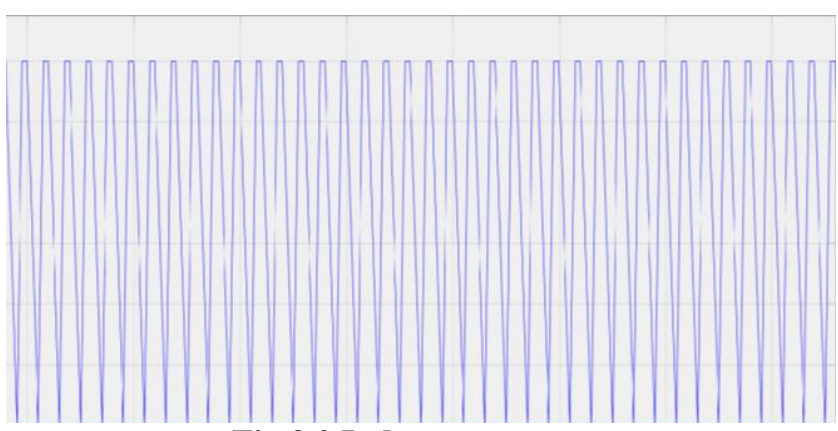

Fig.3.2 Inductor current

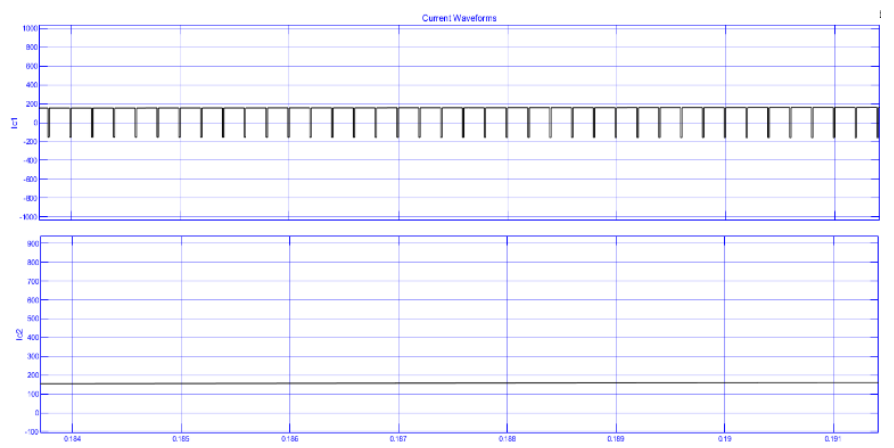

Fig.3.3 Capacitor current

\section{Inverting Buck-Boost Converter}

Conventional buck-boost converter (Inverting) is considered. The simulated results include output voltage (Refer fig.4.1) and output current (Refer fig. 4.2).

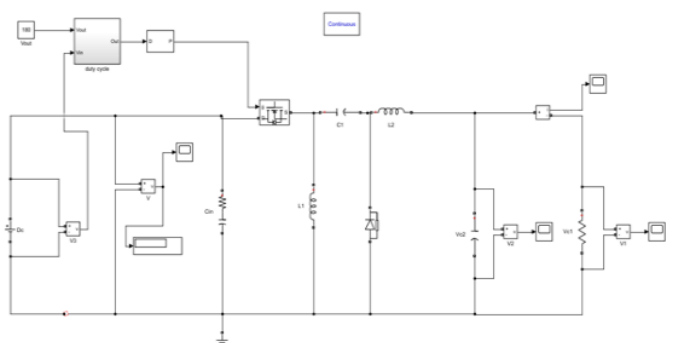

Fig. 4. Inverting buck-boost converter circuit

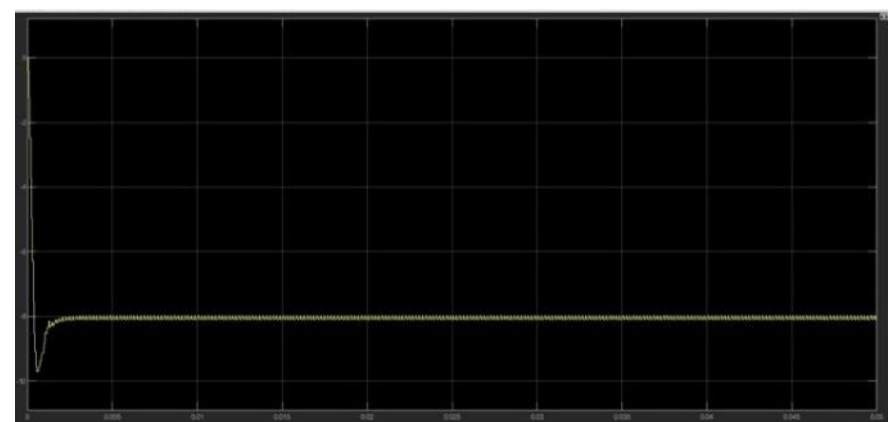

Fig. 4.1. Output voltage of inverting Buck-Boost converter

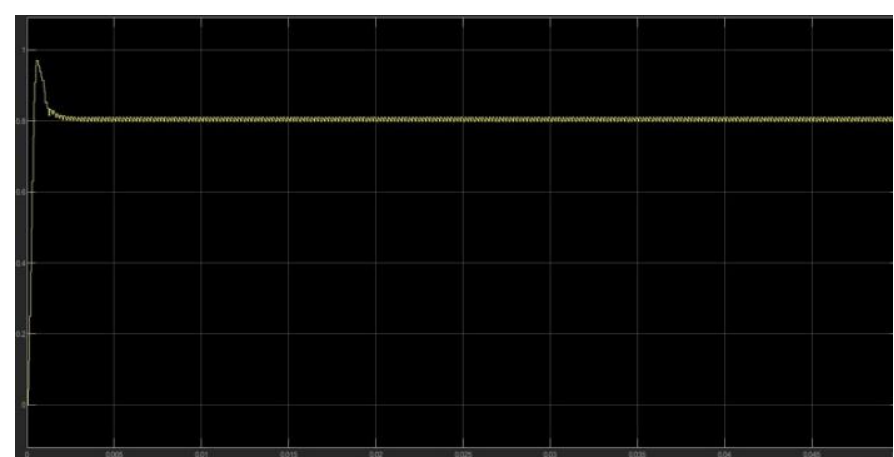

Fig. 4.2. Output Current

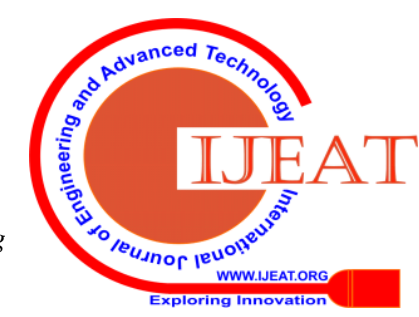


A Non-Inverting Soft Switching Buck-Boost Converter (Closed Loop) and It's Performance Against Various Converters

\section{Simulated Results}

\begin{tabular}{|c|c|c|c|}
\hline S. No & Converter & $\begin{array}{c}\text { Input } \\
\text { Voltage }\end{array}$ & $\begin{array}{c}\text { Output } \\
\text { Voltage }\end{array}$ \\
\hline 1 & $\begin{array}{c}\text { Proposed } \\
\text { Converter }\end{array}$ & $12 \mathrm{~V}$ & $120 \mathrm{~V}$ \\
\hline 2 & $\begin{array}{c}\text { Zeta } \\
\text { Converter }\end{array}$ & $12 \mathrm{~V}$ & $140 \mathrm{~V}$ \\
\hline 3 & $\begin{array}{c}\text { Inverting } \\
\text { Buck- } \\
\text { Boost } \\
\text { Converter }\end{array}$ & $12 \mathrm{~V}$ & $\begin{array}{c}20 \mathrm{~V} \\
\text { (Negative } \\
\text { polarity) }\end{array}$ \\
\hline
\end{tabular}

\section{HARDWARE}

\section{A. Overall Block Diagram:}

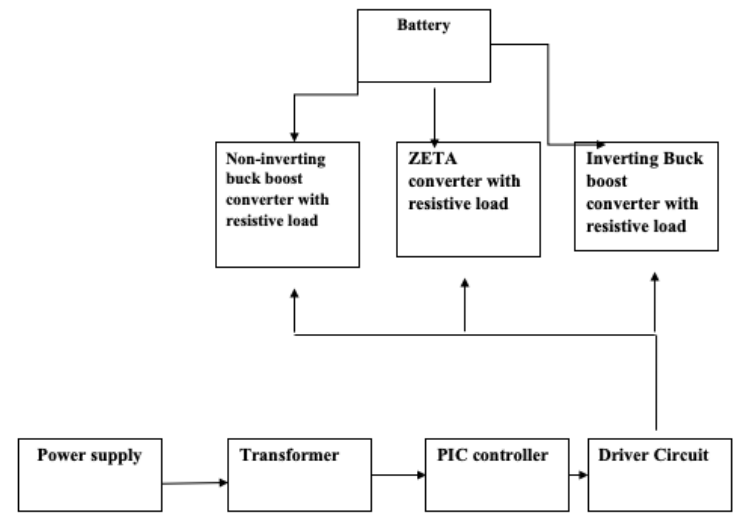

Fig. 4.3 Block Diagram

The hardware consists of three converters connected to the control and driver circuit. The converters are Non- inverting soft switching buck-boost converter (proposed), zeta converter, inverting buck-boost converter. As the supply is given to the control and driver circuit, the proposed converter operates in boost mode. The hardware consists of 3 switches where the first switch can be used for making the proposed converter operate in buck mode. Second switch is used for operating zeta converter. And the third switch is used for operating inverting buck-boost converter. The input voltage and the output voltage can be measured through the connectors provided. Harmonic analyser, power analyser and Digital Oscilloscope can be used for measuring the current and voltage harmonics.

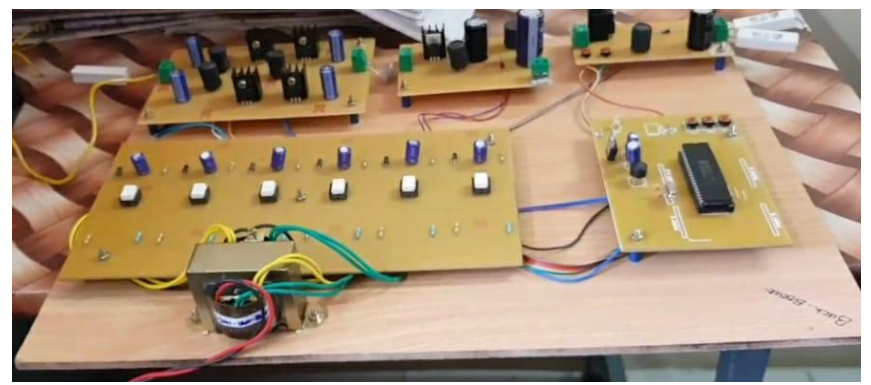

Fig. 4.4 Hardware Prototype

\section{B. Circuit Description:}

\begin{tabular}{|l|l|l|l|}
\hline S.NO & $\begin{array}{l}\text { Component } \\
\text { Name }\end{array}$ & Specifications & Ratings \\
\hline 1 & Mosfet & IRF840 & - \\
\hline 2 & Diode & IN4007 & - \\
\hline
\end{tabular}

\begin{tabular}{|l|l|l|l|}
\hline 3 & Opto Coupler & TLP250 & - \\
\hline 4 & Capacitor & $\mu \mathrm{F}$ & 250 \\
\hline 5 & Resistor & $\Omega$ & \\
\hline 6 & PIC & $16 \mathrm{~F} 778 \mathrm{~A}$ & $5 \mathrm{~V}$ \\
\hline 7 & Transformer & & $12 / 5 \mathrm{~V}$ \\
\hline 8 & Battery & AT12-1.3 & $\begin{array}{l}12 \mathrm{~V}- \\
1.3 \mathrm{~A}\end{array}$ \\
\hline
\end{tabular}

\section{CONCLUSION}

A Non-Inverting soft switching Buck-Boost converter is presented. Performance of the proposed converter in both open loop and closed loop were analysed. A comparison between the proposed converter and various other converters were carried out. Closed loop results were more precise and stable than the open loop. General performance analysis of the proposed converter was carried out along with various other converters like zeta converter, inverting buck-boost converter. The output voltage, stability of various converters were verified by building an experimental prototype.

\section{REFERENCES}

1. S. Waffler and J. W. Kolar, "Comparative evaluation of softswitching concepts for bi-directional buck- boost DC-DC converters," in Proc. Int. Power Electron. Conf., Jun. 2010, pp. 1856 1865.

2. I. H. Oh, "A soft-switching synchronous buck converter for zero voltage switching (ZVS) in light and full load conditions," in Proc. IEEE Appl. Power Electron. Conf. Expo., Feb. 2008, pp. 1460-1464.

3. Y. Zhang and P. C. Sen, "A new soft-switching technique for buck, boost, and buck-boost converters," IEEE Trans. Ind. Appl., vol. 39, no. 6, pp. 1775-1782, Nov./Dec. 2003.

4. H. Kapels, K. F. Hoffmann, Z. Hu "A novel control concept for highefficiency power conversion with the bidirectional non-inverting buck-boost converter", Proc. 18th Eur. Conf. Power Electron. Appl., pp. 1-10, 2016.

5. A. Ansari, H. J. Bergveld, and O. Trescases, "Power electronics for photo- voltaic systems: Devices, circuits and trends," in Proc. IEEE Appl. Power Electron. Conf. Expo. Semin., Feb. 2012, pp. 1754-1761.

6. K. H. Liu and F. C. Lee, "Zero-voltage switching technique in DC/DC converters,'IEEE Trans. Power Electron., vol. 5, no. 3, pp. 293-304, Jun. 1990.

\section{AUTHORS PROFILE}

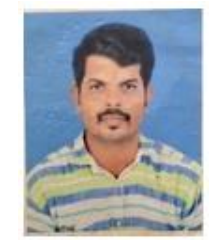

R. Senthil Kumar, received his Bachelor of Engineering degree in Electrical and Electronics Engineering from Thiagarajar College of Engineering, Madurai, Tamil Nadu, India; and his Master of Engineering degree in Control and Instrumentation from Bharath University, Chennai, India. He is currently working in SRM Institute of Science and Technology and pursuing Ph.D. degree in SRM Institute of Science and Technology, Kattankulathur, India. His interests include Artificial Intelligence, Fuzzy Logic and Neural networks.

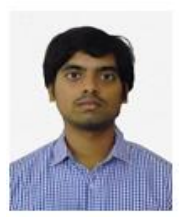

N. Vishaal Balaji, currently pursuing his Bachelor of Engineering in Electrical and Electronics Engineering in SRM Institute of Science and Technology, Kattankulathur, India. His interests include Power Systems, Power Electronics, Renewable Energy and Signal Processing.

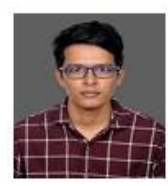

N. Venkatesh, currently pursuing his Bachelor of Engineering in Electrical and Electronics Engineering in SRM Institute of Science and Technology,

Published By:

Blue Eyes Intelligence Engineering \& Sciences Publication 
Kattankulathur, India. His interests include Power Electronics, Digital Electronics and Embedded Systems.

J. Ajay, currently pursuing his Bachelor of Engineering in Electrical and Electronics Engineering in SRM Institute of Science and Technology, Kattankulathur, India. His interests include Power Electronics and Sustainable Energy.

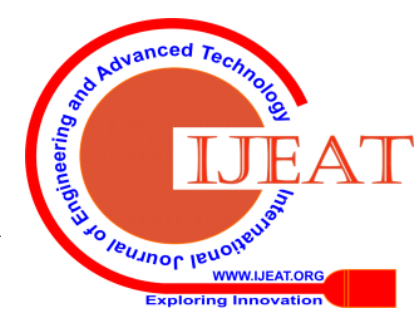

